\title{
Performing on the Boundary of Art and Sport: The Case of Competitive Ballroom Dancers
}

\author{
DOMINIKA BYCZKOWSKA-OWCZAREK* \\ University of Lodz
}

\begin{abstract}
In this article the author sheds light on how dancers act towards their bodies in the exceptionally competitive environment of competitive ballroom dancing. I also show how constantly performing on the boundary between two worlds, art and sport, and reconciling conflicting requirements influences perspectives on the body, how it is used, and how it physically changes. Drawing on specific examples from the field, the author argues that competition, the use of objects, appearance, emotions, and charisma during a ballroom performance are all socially created, actively reconstructed through social interaction, and shaped by institutional rules. The social context of those actions, which is formed by institutionalisation, high competition, and the aesthetics of the upper social classes, produces a specific approach to the body: treating it as an efficient tool to obtain social status. This tool requires both sharpening (strategies for constructing its effectiveness) and polishing (strategies concerned with aesthetics and transforming one's appearance). The conclusions of the research include the finding that ballroom dancing involves the direct embodiment of cultural norms and the subordination of the human body to the ideas of the bourgeois classes. The above insights are based on data collected during a six-year ethnographic study in the social subworld of competitive ballroom dancing.
\end{abstract}

Keywords: ballroom dance, sport-sociological perspective, body, institutionalised competition, social aspects of leisure

Sociologický časopis/Czech Sociological Review, 2019, Vol. 55, No. 3: 369-392

https://doi.org/10.13060/00380288.2019.55.3.471

\section{Introduction}

Sociological interest in dance has so far concentrated on studying such genres as ballet, tango, exotic dance, modern dance, and traditional folk dances from all over the world. Ballet, in particular, is a very well-researched area of sociological interest. There have been numerous types of research investigating the balletic world, from the socialisation of ballet children [Nelson 2001] to research on ballet careers and numerous studies on retiring dancers and teachers [Daly 1997; Dietz

\footnotetext{
* Direct all correspondence to: Dominika Byczkowska-Owczarek, Department of Sociology of Organization and Management, Faculty of Economics and Sociology, University of Lodz, Poland, e-mail: byczkowska.owczarek@uni.lodz.pl.
}

(C) Sociologický ústav AV ČR, v. v. i., Praha 2019 
1994; Goldberg 1997], to a personal understanding of the ballet experience [Kolba and Kalogeropoulou 2012]. There has also been a great deal written written about exotic dancing-about it being an example of female body commodification, about the strict rules of the female ageing processes, about its connection to prostitution, or about the self-esteem of dancers [Rambo, Presley and Mynatt 2006].

There are numerous papers depicting traditional folk dances in many parts of the world that address their role in creating local bonds, the relationship between movement and the landscape, their history, or upbringing through traditional dance education [e.g. Grau 2005; Kubinowski 1997; Blazekovic 2010]. Contemporary and modern dance has been researched in relation to ballet (e.g. contrasting the perception of a dancer's body), and there have been numerous studies on these genres in the study tradition relating to postmodern dance [Daly 1997; Desmond 1997; Foster 1997; Goldberg 1997; Germain-Thomas 2017; Hanna 1988; Kraus 2005].

Ballroom dancing, however, has become an interesting topic of sociological, ethnomusicological, and anthropological interest in the last two decades. The popularisation of ballroom dance television shows has attracted the attention of social researchers and resulted in various publications dealing with such topics as the origins of ballroom techniques [Davis 2015; McMains 2009; Taylor 1998], the researcher's own transformation while practicing ballroom dancing [Bosse 2015; Ericksen 2011; Picard 2002, 2006], issues of beauty and appearance as a key characteristic of this genre [Bosse 2015; Ericksen 2012; Marion 2008], and the corresponding stereotypical gender division [Aldrich 1991; Lepecki 2006; Picard 2006].

For a long time, dance has been given no serious sociological attention as Helen Thomas observed [1995]. This type of human activity has been treated as a 'minority concern'; therefore, how diverse and common it is are matters that have not been addressed sufficiently. Nonetheless, from a sociological perspective, dance culture, as well as particular elements of dance, such as body posture, rhythm, costume, steps, and figures, are strictly interrelated with the culture and philosophy of a society [Hewitt 2005; Kubinowski 1997:13-16]. Each of the elements of dance, the movement patterns used, are part of the culture and reality of the community in which it originated. The specific meaning and the aims of the dance (for example, magical, ritual, entertainment, etc.) are evidence of the values of the community and the mental qualities of its members. Dancing in many traditional communities is an activity that maintains social order, especially in relation to the roles of women and men [Kubinowski 1997: 100].

In addition, knowledge of common dance rules, such as asking someone to dance or behaviour while dancing, is as important as knowing the steps and is considered necessary to master the style [Aldrich 1991; Olszewski 2008: 76]. In the context of the transmission of social values, ballroom dancing can be described as a dance of the white, bourgeois classes. It embodies the values of these social groups, especially in the case of standard dances [Bosse 2007: 28, Thomas 1995: 2]. 
As Caroline J. Picard [2006: 89] puts it: 'an interesting facet of ballroom ... is that gender, inscribed using heterosexual (and aristocratic class) stylus are hyperbolically played out'. Unlike their male partners, women 'are expected to express unbridled emotion ... the women embody and enact conventional notions of upper-class femininity in an exaggerated fashion ... and surrender to male leadership'.

The numerous works dealing with dance in social and cultural contexts prove that referring to the social construction of human embodiment has become a general sociological issue. The way humans perceive, make use of, and transform their bodies is shaped by their experiences, both interactional and social. The human body exists, first and foremost, in one's consciousness, constituting the center of our 'being in the world' [Merleau-Ponty 2001]. Marcel Mauss [1973] introduced the notion of techniques of the body, and he perceived the body as a tool which needs to be culturally and socially defined. This equally applies to its basic functions, such as standing, walking, sleeping, sitting, or the positioning of the head and shoulders, as well as the styles of more complex functions, such as swimming and the use of objects. One's physical capital is socially created and manifests itself through eating, walking, and other elements of physical existence [Bourdieu 1977]. This paper is intended to support the aforementioned approach by giving the dancers a voice and shedding light on their actions concerning body work in the exceptionally competitive environment of ballroom dancing. It also shows how constantly balancing on the boundary between two worlds, of art and sport, and reconciling the conflicting requirements influence perspectives on the body, how it is used, and physical change in the most literal manner.

Ballroom dance, as understood in this article, refers only to competitive, institutionalised, standardised ballroom dances as performed during tournaments. According to the division of World Dance Council, the dances are: International Standard Waltz, Viennese Waltz, Quickstep, Tango, Foxtrot, and International Latin- Rhumba, Cha-Cha-Cha, Paso Doble, Samba, and Jive. The competitive ballroom ${ }^{1}$ dance culture is presented in this article from a sociological viewpoint, supplementarily drawing also on anthropological, ethnomusicological and gender or dance studies perspectives. Ballroom dancing understood more generally as simply dance forms in which people dance in pairs, other types of social dances, and ballroom genres danced for pleasure, not competition, are beyond the scope of this article.

\footnotetext{
${ }^{1}$ I use the term 'competitive ballroom dance' throughout the text when it refers specifically to the competitive practice. If the part of the text refers to the genre generally, I use the term 'ballroom dance/dancer'.
} 
The study described in this article was conducted among Polish competitive ballroom dancers, who act in a particular cultural and historical context. In Poland, the history of modern, competitive ballroom dancing starts before the Second World War. Marian Wieczysty, the legendary founding father of this genre in Poland, established a dance school and continued to teach dance during the war. However, for the post-war, communist government, such 'bourgeois dances' were ideologically unacceptable. Only after Joseph Stalin's death in 1953 and the loosening of strict ideological regulations was Polish ballroom dance able to develop. In 1985, the Polish Dance Association (PDA), the biggest dance association in Poland, was established. Its work focuses mainly on the development of competition in DanceSport, ${ }^{2}$ but also in other styles. The PDA has 16 regional branches. The study was conducted during tournaments organised by the PDA and among dancers affiliated with this organisation.

Therefore, on the one hand, the Polish social context influences the organisational and cultural aspects of practicing competitive ballroom dance. For example, a feature specific to Poland (or Eastern Europe) is the division into private and state-funded dance clubs organised in cultural centers. Another specific feature is the development of a competitive ballroom community that accompanied the post-communist transformation. During the communist era, the community used to be much more inclusive, since the railway network made it possible for less wealthy dancers to participate in competitions. In the last three decades, as public transport connections have shrunk, it has become much more elitist.

On the other hand, the process of teaching and practicing DanceSport is based on international regulations. Polish dancers participate in international tournaments, also in mixed nationality pairs, learn from foreign trainers, and take part in workshops in other countries. The PDA is one of 59 members of the World Dance Council, the organisation that sets the institutionalised rules for competitive ballroom dancing worldwide. This organisational order serves as a steady context for ballroom dancers, including Polish ones. As Jonathan S. Marion [2008: n.p.] puts it: 'each dancer is simultaneously a member of their national culture and of the ballroom culture in distinct but also inextricably interrelated ways. ... It's not by random happenstance, after all, that dancers from disparate countries can easily dance with one another in the absence of shared verbal language'. They share an incorporated reality in common, one that is constructed through acculturation in dance clubs and at tournaments.

2 The World DanceSport Federation defines DanceSport as follows: an activity that combines sport and dance and that allows the participants to improve physical fitness and mental well-being, to form social relationships, and to obtain results in competition at all levels. Competitive DanceSport in a wide variety of dance styles and forms is practised within the internationally recognised and organised competition structure of International DanceSport Federation (www.worlddancesport.org). DanceSport is thus not limited to competitive ballroom dances, but also includes such genres as Street Dances, New Vogue, etc. 
An important context of international institutional competitive ballroom dancing is the codification of both Latin and standard dances, which began in the 19th and 20th centuries [see Davies 2015; McMains 2009, 2019; Taylor 1998]. Associations of teachers, dancers, and musicians ascertained and wrote down the rules of each dance and its basic steps. At the same time, various changes in lifestyle occurred, such as urbanisation, industrialisation, and having free time, and this increased participation in ballroom dancing and all types of social dances. The unification and codification of dance steps, rules, figures and, subsequently, shoes and gowns began in the early 1950s. These rules and definitions determine the specific nature of bodily movements in ballroom dancing and the career paths of dancers. The course of such a career path is formally specified, and each dancer must go through several levels and classes-from the lowest level, Level E, to the highest, Level A, and eventually proceeding to the international class, Class S. A dancer starts without any ascribed class, and by participating in training sessions he or she learns the dances, which are later performed in dance contests and judged. Dancers train in pairs, so an individual dancer sometimes has the same partner for many years. They participate in competitions, and they receive one score as a couple. What counts in progressing to each subsequent class is the number of first, second, and third places in dance contests and the total number of other pairs this couple beats. ${ }^{3}$

Participating in dance contests is the main activity around which dancers organise their training. In the first years of dancing, when the dancers are young children, ${ }^{4}$ they participate in smaller contests, usually organised in the same province. Later, as they move on to higher and higher levels, the dancers participate in national and international contests. They will travel to different countries for one or two days while still attending school, and they will train three, four, and sometimes even five times a week. The rivalry and determination to win increases over time.

The main activity on which the dancer's success depends is participating in contests, where judges use the 'skating system' to calculate scores. The system consists of eleven rules, ten of which apply in the final round. The first rule relates to the preliminary rounds. For each dance, the judges must grade the number of couples who will advance to the next round. A couple's score is the sum of scores received from all the judges. Usually, the number of couples who can participate in the next round is known in advance. Rules $2-4$ determine the way couples receive grades in the final round. In the final round, the judges award couples a place in ranking numbering from 1 to 6 , not scores, which means that no ties are possible. Rules 5-8 are for tallying the final scores for each dance separately, and rules 9-11 compile the final overall ranking of couples in a dance category.

\footnotetext{
${ }^{3}$ For example, if a couple participates in a big contest in which 100 couples are participating, and they take second place, their outcome will be 98 .

${ }^{4}$ The ballroom dancer's career may begin as early as 5 or 6 years of age.
} 
The skating system is, as the above description shows, quite formalised. It also increases competition. The fact that there can be no ties influences some of the dancers' controversial behaviours, such as trying to catch the judges' attention with erotic glances and by performing dance figures that are officially not allowed in a particular dance category. The system is one of the main determinants that make this activity sport-like. The dances themselves are formalised. Each dance has a specified outline of elements, such as a certain rhythm and tempo, to which the dancers must conform.

Having presented the context of competitive ballroom dancing, I will illustrate several issues that determine the specific nature of competitive ballroom dancing as a social activity that focuses on the body. In the next section, I will describe the methodological issues of the research. Following that, I will explain how certain institutional rules, such as formal regulations, traditions, dance education, and also the very strong rivalry in the world of competitive ballroom dancing, influence the way in which the dancers use their bodies, the way they train, and how they perceive and present themselves. In subsequent sections, I will explain the meaning of the use of certain objects, the appearance of the dancers, and issues relating to emotions and charisma during the performance of a dance.

\section{The research methodology}

The research set out from an assumption about exploring the social subworld of competitive ballroom dancing. The actions undertaken by dancers concerning the training, transforming, perception, beautification, and eroticisation of their bodies proved to be crucial to understanding the culture of competitive ballroom dancing. In any genre of dance, a dancer's body is their first and sometimes only communication tool, and the first one by which they are judged. Dancers incorporate certain dance knowledge and experiences, learn how to use their bodies, and transform them in order to have the best tool possible. They use their bodies to build their identities and to construct their position inside the group.

The participants of the research were a part of a larger competitive ballroom dance community, practising the genre in the institutional frames of the Polish Dance Association. The participants consisted of female and male dancers in ages ranging from 15 to 29 , male judges aged between 45 and 55, and male and female trainers between the ages of 35 and 55, with whom I conducted semi-structured and video-elicited interviews. The majority of the twenty interviewees were competitive ballroom dancers; fourteen were former or active amateur dancers. ${ }^{5} \mathrm{~A}$ sig-

\footnotetext{
${ }^{5}$ In Poland, ballroom dancers usually decide to stay amateur for as long as possible, instead of becoming professional, as there exist separate tournaments for both categories. As there are more amateur dancers, there is much greater competition at those tournaments, which dancers prefer, as it gives them the chance to develop their skills.
} 
nificant number of them performed more than one role-for example, trainer and judge, dancer and judge, dancer and teacher, etc.-and it would be difficult to give their precise self-definition. Most of them were settled in central Poland, in small towns and big cities, with some working or dancing for clubs in two or three cities (and also in other regions of Poland); therefore, they had no single place of residence.

The rest of my research participants were flamenco dancers, belly dancers, historical and antique dancers, ${ }^{6}$ hula dancers, dance instructors, choreographers, and judges. They were all female, because of the feminisation of these dance genres, they ranged in age from 23 to 31, and they lived in big Polish cities.

I met the participants of my study at the ballroom dance tournaments where I conducted the observations, and I also approached them personally in their dance schools, asking them for a talk or an interview. None of them rejected my request, and most of them felt gratified that someone appreciated their hard work, which is often perceived as a light, effortless pastime. At that time, I had been practising belly dancing for five years, which helped me to understand some of the problems my interviewees spoke about, and I was also able to get to know dancers of more than one genre. The problems referred mostly to verbal communication while teaching and learning to dance, the role of the body as the dancer's tool for work, and the use of objects such as a mirror, shoes, and gowns.

The research was conducted using grounded theory methodology [Charmaz 2006; Strauss and Corbin 1990] and several data-collection techniques comforming to the requirements of triangulation [Charmaz 2006: 14-15]. I started my research with interviews. They gave me the initial information about my subject of study and descriptions of the interviewees' experiences of their own bodies. It soon turned out that speech is not a sufficient tool for obtaining rich data on the human body. Therefore, I turned to photos and video-elicited interviews. Their main advantage is that it makes it possible to interpret data given by people whose knowledge is incorporated and that they are often not aware of. This makes it possible for us to acquire what is sometimes astonishing knowledge [Konecki 2005a: 46] about the body or dance. ${ }^{7}$

Additionally, I conducted several observations at ballroom dancing competitions. What turned out to be a problem was my lack of insider knowledge. Therefore, I tried to get the dancers or other spectators to comment on what was happening.

As appearance and movement are vital components in any dance, I applied photo and video analysis [Knoblauch et al. 2008; Konecki 2005a]. These techniques enable the researcher to perceive meanings without verbal communication. Photos and video recordings give us the possibility to see how people use their bod-

\footnotetext{
${ }^{6}$ Antique dance is composed of movements reconstructed from antique Greek paintings. 7 Useful information on visual methods and their critique may be found in Konecki [2005a] and Knoblauch et al. [2008].
} 
ies, how they act through them, and they allow us to deduce what kind of meaning people give to their bodies. In each dance, the gestures and moves depend on the convention of the dance (e.g. modern jazz, belly dancing, ballet), because every dance has a certain philosophy deriving from its culture [see also Thomas 1995: 6]. For example, ballet, which developed in Christian culture, should be very delicate and light, creating the illusion of floating on air, as heaven is a great value in these societies. At the same time, African folk dances are performed very much on the ground, on bent knees, in an inclined body positions, as those societies cherish Mother Earth [Grau 2005: 149]. This may cause a difficultyin understanding different moves and gestures (as in observation), and that is why we need to ask people from inside the given social world to comment and explain.

Autoethnography was applied in my research as a supplementary method. My personal experience with another dance genre-belly dance-helped me to understand some of the research participants' experiences which I have already mentioned. Autoethnography is a method that may be used by a person who becomes a part (sometimes the main part) of the studied phenomenon [Wall 2008: 39; Anderson 2006]. This technique is useful in matters that require understanding how one may change the way one experiences one's body, or how one can receive knowledge that is set inside somebody else's embodiment. ${ }^{8}$

The aim of the ethnographic description [Gobo 2008: 5, 8; Kleinknecht 2007: 8; Prus 1994: 21-27] as part of my research was to show the background, the context of the activities, and the perspectives associated with the phenomenon of the social construction of the human body. It makes it possible to learn about the initiating and intervening conditions that have a significant impact on the social construction of the human body (e.g., competition, the processes of institutionalisation).

In the process of data analysis, I applied the procedures of grounded theory methodology. These include coding (open/substantial, selective, theoretical, and axial), preparing theoretical memos, theoretical sampling, triangulation, the constant comparative method, in vivo codes, diagrams, and a conditional matrix [Charmaz 2006; Strauss and Corbin 1990]. The process was reapplied to the gathered data several times for the whole six-year period of the research.

\section{Reconciling the conflicting requirements of art and sport}

The difference between dance and sport resembles that between an aesthetic and a purposive or functional activity (using means to obtain a specifiable outcome). In the latter, the means are independent of the end; it may be achieved in any way.

\footnotetext{
${ }^{8}$ It is beyond the scope of this article for me to focus on autoethnography in detail. Useful information on autoethnography can be found in Anderson [2006] or Byczkowska-Owczarek and Jakubowska [2018].
} 
As Graham McFee indicates: 'for some sports ... we can specify the end broadly independently of the means of satisfying that end'. In the case of soccer, any goal is one goal for the team; the means are not crucial if they follow the rules of the game. David Best [1978; cited in McFee 1992: n.p.] distinguishes between purposive sports (e.g. soccer, rugby, volleyball) and aesthetic sports (e.g. rhythmic gymnastics, figure skating). We may watch purposive sports for aesthetic reasons, but that is not their critical role.

There is an interesting division between what is aesthetic and what is artistic, where aesthetic refers to something beautiful, but not necessarily done on purpose (e.g. a sunset). Artistic, however, refers to objects made purposefully by an artist. What is more, to understand art, not only beauty, it is crucial to refer to cultural codes. Just as when listening to a song or poem one must understand the language in which it is written, understanding meanings presented in dance requires an understanding of the cultural code in which it was created [McFee 1992]. That is what distinguishes art and dance from sports, even those with a more aesthetic focus.

An example of the dual identity of competitive ballroom dance as a sport and art is the issue of it being accepted for the Olympic Games. One of the confusing issues, specific to this genre, is the image of a male dancer (e.g. makeup). As Picard [2006] puts it, this kind of 'gayish look' causes persistent anxiety in the Olympic community and is one of the arguments against including competitive ballroom dancing among the Olympic disciplines. This debate has been waged for years, and opinions are divided even between dancers. As some of them claim, the Olympic motto of Higher-Faster-Stronger cannot be successfully adopted in the genre without losing the artistic aspect of the dance. However, when it comes to physical effort, research cited by Picard indicates that muscular exertion and breathing rates are similar among competitive ballroom dancers and cyclists, swimmers, runners, or decathletes. Therefore, the body itself and the actions undertaken to control it and to perform through it are similar in ballroom and (other) sports. The debate itself is an example of the problems with defining and self-defining ballroom [see also Thomas 2003]. At the same time, as Jonathan S. Marion states [as cited in Ericksen 2012: 52], 'ballroom is not judged through its physical execution. Judges do not actually dance with the competitors to assess their aptitudes. Rather, competitors are judged on the appearance of their performances'. Therefore, the appearance and impression produced by the pair are equally important in order to succeed in this genre. The exclusion of more balletic and acrobatic figures from competitive ballroom dancing are actions demonstrating that some institutional efforts are also undertaken in order to preserve the character of ballroom dancing as a genre on the boundary of art and sport [Picard 2006].

The idea of the perfect sportive body, as adopted in the culture of the Olympic Games, associates a strong, fast, and muscular body with a beautiful one. Issues of race or gender become more controversial as discussions around the Olympic Games develop. Recent decisions on the participation of sportswomen 
with high testosterone levels (e.g. the case of Caster Semenya) show that Olympic competition favours certain cultural notions of femininity/masculinity.

In the case of ballroom dance, two stereotypes exist that concern the human body. One of them is the strict division between feminine and masculine, which cannot be diminished as it is a central feature of the genre. The other, which is informal but quite important, is deeply rooted in racialised preferences for certain dance genres [Bosse 2007]. This contrasts with the ideas of the Olympics. To include ballroom dance in the Olympic Games would mean that its implicit racism could become institutionalised-dancers might receive better scores in the Latin or standard style, depending on their racial features.

Competitive ballroom dancers face many limitations and challenges. Some of them refer to bodywork, others to appearance, and also to their individual features. In this section, I will present the most important aspects of dancers' everyday work that are the most significant in terms of meeting the twofold expectations of competitive ballroom dancing — as an art and as a sport.

\section{Competition}

Competition is one of the most prominent aspects of ballroom dancing, and consequently, like in any other sport, dancers want to make every aspect of their dancing decisions and activity effective. By 'effective' I mean in this particular context goal-oriented, with reasonable management of one's physical, financial, interactional, and other efforts, and a focus on actions that offer the highest possibility of success in a tournament. The skating system applied in the judging of dancing determines how dancers and their trainers set their development goals and how they train or participate in competitions. Throughout the whole period of my research, effectiveness seemed to characterise each and every element of the competitive ballroom dancers' reality: the way they trained, their choice of trainer, the shoes, gowns, and tailcoats they wore, the makeup and hairstyles they had, and the way they trained their bodies. Competition in ballroom dancing is so fierce that there is no time to waste on ineffective decisions or activities that produce little or no benefit. The strict rules of judging give ballroom dancing a sport-like nature and impose a specific way in which the dance should be performed.

Additionally, a specific aspect of competitive ballroom dancing, like any other activity in which performance and impression play a huge role, is that it is impossible to judge it objectively. The dancers never know how they will be judged, as the judgment is not based on objective criteria; ${ }^{9}$ therefore:

You can compare it to a cycling race, a multi-stage one where [the cyclist] does not have to win any one of the stages, but could still win [the race] ... but this is different.

${ }^{9}$ Unlike in sports, even aesthetic ones. 
There it's timing, everything counts, right? And he cycled so fast that he had the shortest time. What's more, if he already knew he was in the first place and didn't have to race the last two stages, he would only go safely. That's what the leaders often do, let the others race. But this is a little different. Here we race to the end. I go to the competition to race, right?

Male ballroom dance trainer, judge, former dancer, age 50

Although the evaluation system can be a source of controversy, the dancers seem to accept the rivalry and are even content with it. The following statement from one trainer and choreographer illustrates this well:

In this sport, in this dance, I like to fight right to the end, but with a smile on my face.

Development occurs through competition, the desire to be better than others. Rivalry in competitive ballroom dancing is the result of the basic logic of assessing the dancers and giving them points - comparing them. A dancer cannot simply be good or very good; he or she must be better than the other dancers.

Likewise, interpersonal relationships between dancers are dependent on the effectiveness of their common dance. At the initial stages of their career, all romantic relationships are unwelcome, as any problems they might cause would influence the couple's ability to participate in contests. This is not an official rule, and very often it is also not stated explicitly by the trainer either. It is simply a way of increasing a couple's effectiveness. Like in business or a marriage of convenience, simple camaraderie is the best relationship. As one male ballroom dancer put it:

Researcher: How do you do it, if you argue with your partner, or you simply dislike her, and then you have to go on the dance floor and show positive emotions? How do you do that?

Dancer: You can't describe it, you have to learn it. It's experience; you have to recalculate it for yourself. It pays off ... It doesn't pay off if I sulk. You just have to do your job.

Male ballroom dancer, age 16, dance level: A-standard/B-Latin

As the research results show, choosing the right dance partner depends on their dance level, age, financial situation (the ability to invest in participating in contests, expensive gowns, etc.), height, and physical attractiveness. The latter is important regarding the judges' point of view, not the dancer's. It is only in later years, however, when dancers spend so much time with their dance partners, traveling abroad to train or participate in competitions, that they often marry their dancing partners. This may also be due to the fact that along with developing their career, dance pairs plan ways of continuing their career by working as trainers or founding a dance club together, thereby more formally binding their lives together. 
Rivalry can only take place within the framework of the formal guidelines set out in the rules and regulations of the PDA. The main objective of these principles is for the dancers to gradually absorb knowledge-in the lower-level classes, technique is the most important thing. Outfits and makeup that are too flashy are forbidden from competition and the use of them may result in the dancers being disqualified. The basic principle of competition is sports justice, i.e. maintaining uncertainty in agon games. ${ }^{10}$ The movements, figures, shoes, and clothing that are permitted are strictly defined by the institutionalised rules. Dancers may be penalised for failing to conform to these rules. Dancers may be disqualified from participating in the dance tournament if they perform outside the repertoire established for a particular dance.

Competition in ballroom dance has many faces, not all of them fair. As the rivalry is so harsh, sometimes it is not enough just to try one's best. Some dancers feel such intense pressure that they resort to other tactics, such as cutting a buckle off someone's shoes, tearing a dress, turning another pair's number upside down, or acting outright aggressively-for example, tripping the other dancer up. ${ }^{11}$ More subtle ways of catching the judges' attention include a pair delaying their entrance onto the dance floor when all other pairs are already waiting to start a dance or beginning to dance a few seconds after the other pairs.

As shown above, there are two dimension to the specific nature of competition in ballroom dancing. The surface level is strictly physical and technical-like in sport. What counts on this level is stamina, strength, good physical condition, and well-trained movements, etc. The dancing pair must perform certain steps or figures in order to be judged for presenting a certain kind of dance. The second and higher level is much more artistic, based on the ability to communicate the cultural code of the dance. The gowns, makeup, smiles, and emotions presented on the dance floor are all meant to transmit meanings and the story behind each dance. The two levels of competition coexist and are developed equally throughout a dancer's career.

\section{The use of objects}

Like in other sports, the choice and use of any kind of object may prove to be decisive for the final outcome. The most important objects that influence the effectiveness of a dance fall into two categories: objects used during training and those used in tournaments. Objects used during competitions include the dancing gowns, the men's outfits, shoes, artificial hair, makeup, artificial nails, but also the dance floor and heel protectors. Generally, the objects that help give the

${ }^{10}$ Roger Caillois, a French sociologist, distinguishes four forms of play, these being Agon, Alea, Mimicry, and Ilinx [Caillios 1958].

${ }^{11}$ All the above-cited examples are taken from the interviews with ballroom dancers. 
dancer the right look must meet several standards. First, there are formal criteria. The official rules state in which class certain types of outfits can be used (like sequins, frills, high heels, or makeup). If the dancer does not obey the rules, they may be disqualified from the tournament.

The second criterion is the effectiveness of the object, such as the ability to perform certain moves when wearing them, the right looks for attracting the judges' attention, the design of the clothing, which is meant to both highlight the strong points in a dancer's figure or skills and hide weaker areas (e.g. a long, standard gown finished with frills helps to hide poor footwork). When using these objects, the dancer adheres to the principle of situational efficiency, in other words, that the object is effective only in a specific situation, such as a tournament (sequins, reflective colours, bras), a training session, or a workshop (the use of bandages). Under other circumstances, the object may become ineffective. To effectively assist the dancer, the object must be predictable and unchangeable. It must give the dancer the maximum confidence and comfort, so dancers use strategies to subordinate the objects. The following excerpt from a former dancer describes such adjustments to the dancers' needs:

The coolest thing about those [men's dancing] shirts is that the shirts are sewn; so you normally sew men's ... women's pants, such as Triumph or those Sloggis ... in a way that the shirt does not become untucked. All the men's shirts have panties ... because when he raises his hand or something, the shirt would untuck itself.

An ex-dancer, female, age 24

The third criterion is much more personal, and the decision depends on the subjective preferences of the dancer. This includes fashion and colours, but also being embarrassed or (un)willing to physically expose larger areas of the naked body.

The dancers' outfits described above are the best example of how sport and art are mixed together in competitive ballroom dancing. Having presented above all the 'sport-like' aspects of the outfits, makeup, and artificial hair or nails, I must point out that they also define the artistic side of the genre. On the one hand, they must be comfortable, but they should also be beautiful, as this is expected from the dancer. It is also judged and has a great influence on the final score.

The clothes play a very important role, as they help the dancer to create the separate reality of the dance. As many of the dancers stated, when they put on the makeup, dancing gowns, and shoes, outside reality seems less and less 'real'. Even though the competitions take place in sports facilities and the audience is wearing everyday clothes (unlike at the theatre or opera), the dancers' look corresponds to the dance convention. Long, shiny gowns with feathers, rhinestones or frills, tailor-made tailcoats, theatrical makeup, gleaming white teeth, and an intricate hairdo transport us back to a competitive ballroom of the 19th century, while short, sexy, fluorescent dresses and black slim-fit shirts and trousers make 
us feel like we are at a party in Latin America. The look is a crucial element of the performance, not only because it makes the show beautiful, but also because it gives the dancers a feeling of being unique and appreciated. It also distinguishes individual dance pairs from each other. If competitive ballroom dancing was just a sport, the dancers would all wear the same, simple outfits to make the judging easier and more objective.

However, the use of beautiful gowns and tailcoats is limited within the official rules of the dance organisations. The competitive ballroom dance organisations that establish all the objective rules also impose strict limitations on the performance of certain steps and figures and the use of particular costumes by dancers in lower-level dance classes. During the tournaments, one of the most important objects is the dance floor. Of course, the dancer cannot choose it, but the pair may decide on which part of the dance floor they want to dance in (in order to be visible to the judges). The dance floor plays a great role in many genres of dance; however, one of the distinguishing features of ballroom dancing is that the dancers must be able to use the dance floor appropriately. This is evidenced by the way the dance pairs frequently talked about 'embedding [themselves] in the dance floor' or 'drawing energy from the dance floor'.

The objects used during the tournaments are not limited to the ones that a dancer uses during the performance. There are also the tracksuits, dressinggowns, and warm socks and slippers that are worn between the judged dances, which help keep the dancer's body warm and are less tiring for the body than the dancing gowns and shoes. Footwear is an object used both during training and tournaments. Its use is also defined by formal rules (for example, referring to the height of the heel). One of the important criteria for evaluating competitive ballroom dancing is the dancer's footwork. The shoes should fit the dancer well; a dancer can, for example, get injured using the wrong shoes. Similarly, very advanced footwear technology exists for basketball players, footballers, and other athletes. As such, footwear is one of those objects that, in the long run, can cause injuries and, more precisely, foot distortion, mostly in the case of girls and women.

During training, the most important objects are the mirror and the dance floor, an elegant but comfortable outfit, bandages, and cameras, et cetera. Amongst these objects, the mirror seems to stand out as very special, as crucial for learning a dance. Without it, the dancer is unable to verify the similarity of his or her own body to the perfect or expressive body [Foster 1997]. The body in dance is a body that looks a certain way. By comparison, when learning and practising yoga, no mirrors are used. An asana's appearance is the result of appropriate positioning directly verified by the teacher; but it is not an objective itself [see Konecki 2005b]. The mirror allows dancers to look at their body from the outside, to distance themselves from it, look at the transformed object, and then transform it into one resembling the teacher's body.

As mentioned above, there are also other objects, not directly involved in the performance, that play an important role during training and preparing for 
the competition. These include stretchy bandages and ointments, which support muscle work and prevent injuries. One dancer describes the importance and use of an object of this type:

Anyway, you have to have straight legs, and I somehow, I don't know, I bent them upwards or something, mine weren't straight. Then at home, I came up with an idea [laughs] of putting on bandages, on my knees, two bandages, and then I danced, and it actually helped me

Female ballroom dancer with no ascribed dance level, without a dance partner, age 17

\section{Appearance}

Another element of competitive ballroom dancing that sets it on the boundary between art and sport is appearance, the beauty of a dancer-For example, the dancer's hairstyle, tan, and makeup, etc. The experience of becoming and being beautiful seems to be part of the foundations of the ballroom dancer's identity and is based on appearance, facial gestures, and moves. What is more, the idea of beauty is highly standardised and is an important element of the community [Bosse 2015; Ericksen 2011]. Of course, the dancer's appearance and looks are not only a matter of beauty, they also form a judging category-a certain number of points are awarded for the appropriate look. The dancer's appearance is how the hard bodywork, daily workouts, and good technique are noticed and awarded. The category of appearance does not end with the costumes themselves. The appearance of the dancer must match the dance convention, so the dancer uses various tactics to properly prepare for the performance. Ballroom dancing is supposed to have an artistic value. This has a direct impact on the dancers' bodies, because a certain type of beauty may determine the chances of success in a particular type of dance (Latin American and standard). As one of the interviewees stated:

In Latin dances, if there are two dancers, a blond and a mulatto [the term used by the interviewee], they will not be equal. It's better for the black one, 'cause it's a Latin American dance. Such things matter. In the standard dances, the blond will be treated better. That's what it is, the impression, although it shouldn't be that way. They should look at the technique. But it's the look of the couple, the impression, that gives a judge a wide way of explaining why he chose this couple, not the other one.

Male ballroom dance teacher, former dancer, age 45

The importance of a couple's appearance also influences the bodywork outside the dance. Young people engaged in competitive ballroom dancing do not have, for example, brightly coloured hair. Some of the dancers who practise Latin American dance dye their hair black and are very tanned, while standard danc- 
ers are not. They conform to the requirements of competitive ballroom dancing, because if they don't, they have to give up training and move to a different social sub-world [see Kacperczyk 2005: 172]. The ability to maintain an elegant and attractive appearance is evaluated during the training; therefore, dancers pay attention to it, because:

Taking care of your image in this little world, it's the same as, I don't know, among movie stars or something like that, right? But besides, you have to take care of your outer appearance ... first and foremost in training, so you always have an ironed shirt, a nice tie, and so on. [The girls] too, well, they are usually in pants, but that's because it's harder to dance in a dress than in pants, but in such elegant pants.

Male ballroom dancer, dance level: A-standard / B-Latin, age 16

There are also aspects of the body that cannot be changed, such as height or eye and skin colour, or where the change would be too invasive-for example, breast enlargement. In this situation, the dancer can remain in the dance genre they are in and accept lower scores and limitations in their career, or they can leave the genre by choosing a convention that more closely matches their body. One example of such a phenomenon is the issue of racial features. One of my interviewees stated that he did not know of any black dancer who could succeed in this dance genre [see also Bosse 2007]. The bourgeois, upper class, Western style is so profoundly inscribed in the practice of standard dances that the idea of beauty and creating an impression seem to be something beyond the reach of people whose natural look varies from the cultural ideal.

\section{Emotions, charisma, and performance}

The participants in my research, competitive ballroom dancers, and also representatives of other genres, spoke convincingly about competitive ballroom dancing as an art, although they also mentioned its sport-like character, which sets it apart from other genres. The dancers perceive themselves as people who perform beautiful shows; thus, there are some factors that make it similar to other genres of dance.

First, like other artistic activities, competitive ballroom dancing is a way of interpreting general truths about the human existence, such as love, passion, and emotions, or issues of femininity, masculinity, beauty, and entertainment, et cetera. Each dance, standard or Latin, has its own story to tell, and it requires an actor to present it in a touching way. For example, the paso doble is a tale about a bullfight. This might seem obvious and simple, but as one of the trainers, a male ex-dancer in his fifties stated, a paso doble figure 'waving a cloth' may be interpreted in various ways. Trainers and dancers say that dancers can 'express themselves' or 'interpret' a dance in their own way, even within the rigid framework 
of competitive ballroom dancing. This self-expression comes only at a very high level, when the body is already a tool that is very much in the dancer's command. One person might dance in a way that suggests catching the bull, the other as if the bull had just wiped out the 'bullfighter'. The same story may be retold over and over by each couple, and each time it may give spectators a slightly different impression. $^{12}$

Each dance has its own atmosphere, mood, and emotions. In each of them, the dancers create a separate dance reality, different from what is happening off the dance floor. What becomes the dancer's actual reality is the story that the chosen choreography is supposed to tell. The dancers' task is to convince the audience, including the judges, of the emotions and impressions they are creating and to believe their story. In order to convince others, the dancers have to believe the story themselves. Their bodily work is just a means of transmitting the eternal story that exists within the dance. Impression plays an important role in the performance of a competitive ballroom dance; thus, it is impossible to make an evaluation objective. This is what makes competitive ballroom dancing an art.

Another specific feature of competitive ballroom dancing, apart from its institutionalised character, is dancing in male-female pairs. ${ }^{13}$ The interaction of two bodies and the virtual emotions in dance have been studied by Caroline Picard [2002: 359-360; see also Aldrich 1991]. Her study shows that, as in most other dances, expression in ballroom dance is based on performing the traditional patterns inscribed in the genre. Female dancers, as noted above, are expected to express emotions freely. At the same time, men are expected to be stoic in any type of ballroom dance: 'stoicism becomes aestheticized and conflated with the very essence of masculinity' [Picard 2006: 89]. Male ballroom dancers also have a uniform look. Their function is to frame their partner's more individual and colourful movements and appearance.

The emotions performed in front of the judges and audience also include erotic passion, which is inscribed especially in the Latin dances. The roles of the seducer and the seduced are culturally assigned, and as one of my interviewees said, they cannot be switched without a reduction in scores. The passion ex-

\footnotetext{
12 Juliet McMains [2019] mentions an important issue of mental conflict amongst ballroom dancers - the incompatibility between self-expression and the rigor of standardised dance expression, when the sense of self-worth is tied to the results of a tournament.

${ }_{13}$ In institutional competitive ballroom dancing, only male-female couples are allowed. A same-sex competitive ballroom dancing movement does exist, where both dancers are male or female [see also Bailey 2011]. This type of competitive ballroom dance is developing in Western societies. However, official associations do not permit such couples to participate in regular contests. Official regulations state that if a same-sex couple participates in a contest, all scores may be annulled. This results in same sex-couples organising their own contests and dance clubs, which are not under the direct influence of international dance associations.
} 
pressed towards one's partner is yet another element that is judged and, as such, it is treated instrumentally. Mutual sexual attraction between partners has little to do with their actual performance.

Another aspect that can be judged as an element of the performance on the dance floor is charisma, or the ability to connect with the audience, the fans, and the judges through dance. According to the interviewees, these characteristics often determine the audience's reception of the couple and attract the judges' attention. The artistic aspect of ballroom dancing is also perceived and accentuated by the dancers themselves, which creates a specific philosophy of uniqueness.

The emotions and gestures that this expression emerges from are not 'real gestures', as the dancer does not experience them 'naturally'; they are also not caused by a particular situation. If the dancer experiences the emotions, it is an effect of performing them. This also requires a specific ability to distance themselves from the performed emotions at the end of the show. In the case of ballroom dancing, the dancers have to cope with two bodies and two ways of expressing emotions. The essence of ballroom dancing is, as Peters puts it [as cited in Picard 2002: 358], 'an expansion of self through another', to mutually feel the dance through the partner's body. The principles of the ballroom technique rely on several points in the dancers' bodies through which the communication between partners takes place. In standard dances, these points in the body are the frame and a line from the hip to the upper chest. Through long, intensive practice, dancers incorporate their partner's body into their own bodies, like a unique type of tool [Merleau-Ponty 2001]. Through experience, they learn the shapes, tension, and centre of gravity of the other dancer's body and the subtle signals it emits, and they subconsciously subordinate and attune themselves to them, thereby creating one joint movement together.

\section{Conclusion}

The results of my research presented in this article clearly show that the uniqueness of ballroom dancing stems from two contrasting expectations: sportive and artistic. The subculture of high competition is characterised by the demanding bodywork of the dancers on the one hand and the increased opportunities for refining and enhancing one's appearance on the other. This high competition is accompanied also by efforts to regulate what the participants are and are not allowed to do. The authorities of ballroom dancing organisations take actions to prevent it from becoming just another sports discipline and to preserve the ability to assess the dance. Therefore, the organisations establish institutional regulations that determine the number of figures performed and how elaborate or fancy the dancing costumes can be. The performances must have a standard number of dancing styles, the rhythm of the dance music, the number of couples on the dance floor, as well as the age and class of the participating dancers. Otherwise, 
the judging rules would leave too much to the subjective impression of the judges and it would be impossible to compare and assign dance classes. Additionally, the adopted system of marks and the context of judging - judges have fewer than two minutes to assess and compare six couples on the dance floor-encourage the dancers to use tactics to attract the judges' attention that are not related to their dance skills.

In order to satisfy the expectations of physical strength, stamina, and technical skill, the dancer has to exercise for several hours almost every day. Such practices are, in my research, called 'sharpening the tool'. The term refers to all the actions of a dancer and his or her partner that are aimed at physically preparing for the performance. These include, for example, frequent training, taking part in dance camps, muscle-building exercises, et cetera. This work not only affects the perspective in which the dancers perceive their own body, it also directly shapes the body, the biological dimension of the dance. 'Sharpening the tool' satisfies the sportive requirements of ballroom dancing.

The second category identifed in my research, explaining the specific bodywork of ballroom dancers, is 'polishing the tool'. The notion refers to the practices dancers engage in to prepare as best they can for a tournament in terms of their appearance. When a ballroom dancer performs at a tournament, their body must be properly prepared. These practices include tanning, makeup, hairstyle, nail work, teeth whitening, and so on. These are necessary so that the effort the dancers put into 'sharpening the tool' can yield the desired effect- to be noticed by the judges during a tournament. These activities have a great influence on how the dancer perceives his or her body, also in terms of gender roles. 'Polishing the tool' satisfies the artistic side of ballroom dancing by transmitting the cultural codes of the genre.

Both practices, 'sharpening' and 'polishing the tool', combine the specific nature of ballroom dancing in a dancer's body and making this genre a part of his or her physicality. 'Sharpening the tool' exemplifies the sportive aspect of ballroom dancing while 'polishing the tool' encompasses practices that differentiate this genre from a sport and relate it much more to other forms of art. It is in the body of a dancer that all the cultural qualities present in a genre are incorporated and are made visible and spirited. The text presented examples of other bodily subcultures, such as yoga or sports. Each of them creates a different cultural context. Thus, they each produce different bodies-as-tools.

The process of embodying culture is realised in stages. The dancer's body is trained and gradually, in stages, yields itself to the dance from a young age. More and more body parts become involved in the performance [see also MerleauPonty 2001: 162], so that a child dancer may use his or her legs and arms, while the highest S-class dancers might employ in a dance movement even their fingers to express the rhythm of swing.

Human bodies are always set in the context of a time, culture, and individual biography. The culture of each social world or group creates its own norms 
and values referring to the human body, and its members must obey these standards of perception, making use of and transforming their bodies. This fact puts the human body, if not at the centre, then within an area of sociological research that embraces other types of social phenomena, such as religion, the economy, gender, class relations, etc.

This phenomenon is made explicit and visible through the case of the dancers presented in this article. Dancers are judged only on the basis of their performance. They embody cultural norms directly and strongly, probably more strongly than in other professions, where the results of a person's work may be judged differently - for example, according to its effectiveness (as in the case of construction workers or martial arts fighters) or in terms of intellectual performance (as in the case of physicians or academics). Shedding light on ballroom dancers' actions in the area of body work not only helps us to understand this subculture from an ethnographic point of view, but also allows us to observe the relationship between cultural context and the human body. Additionally, it provides us with a series of individual stories in which each dancer expresses their unique perspective on participating in this culture. These stories make it clear that social phenomena become a reality through the actions of social actors, which are based on individual interpretation. Each one of them tells a common story through their own body.

Dance and sport let social actors express themselves physically and emotionally. Also, any genre of dance, or any type of sport, is made up of rules that must be obeyed. The everyday practice of mastering one's own body is yet another aspect that makes these actions comparable. However, these two practices are also quite dissimilar in some respects. The idea behind sports is situated less in the performance and more in the final outcome. Interpretation in sport refers more to the decisions of judges - it is not the task of the spectators or audience to interpret the outcome, as it is usually defined in numbers. The situation is quite the reverse in the case of dance. Meanings are being transmitted throughout the performance and it is also the audiences' task to interpret the meanings within the movements and to 'read' the story told by the dancer's body. At the same time, in ballroom dance, as a human activity on the boundary of sport and dance, international rules apply and it is quite easy to dance the tango or cha-cha-cha with a dancer from the other side of the world whom one has just met.

What seems to be the most fundamental difference is the relationship of sport and dance to the meanings they bear. In both these activities their meanings are taught as a part of the training process. Communication between sportsmen entails communication between people who know the rules of the sport. In dance, because the movements have deeper meanings, the act of performing them becomes the act of interpretation. Communication between dancers, or between a dancer and the audience, is about communication among people who share similar cultural meanings and know how to perform/show/transmit/ interpret the same story. The difficulty of ballroom dance, as perceived by the dancers themselves, lies in the ability to achieve a balance of actions between the expectations of two and to some extent contradictory subcultures-art and sport. 
DOMINIKA BYCZKOWSKA-OWCZAREK works in the Sociology of Organization and Management Department, Faculty of Economics and Sociology at the University of Lodz in Poland. Her book Body in Dance. Sociological Analysis presents the outcomes of a six-year study on ballroom dancing as a social activity. Her main scientific interests are symbolic interactionism, grounded theory methodology, sociology of the body, sociology of dance, and ethnographic research.

\section{References}

Anderson, L. 2006. 'Analytic Autoethnography.' Journal of Contemporary Ethnography 35 (4): 373-395, https://doi.org/10.1177/0891241605280449.

Bailey, M. M. 2011. 'Gender/Racial Realness: Theorizing the Gender System in Ballroom Culture.' Feminist Studies 37 (2): 365-386.

Blazekovic, Z. 2010. 'Salonsko Kolo: Dance of Nineteenth-Century Croatian Ballrooms.' Dance Research 12 (2): 114-126, https://doi.org/10.2307/1290991.

Bosse, J. 2007. 'Whiteness and the Performance of Race in American Ballroom Dance.' Journal of American Folklore 100 (475): 19-47, https://doi.org/10.1353/jaf.2007.0002.

Bosse, J. 2015. Becoming Beautiful: Dance in the American Heartland. Champaign, IL: University of Illinois Press, https://doi.org/10.5406/illinois/9780252039010.001.0001.

Bourdieu, P. 1977. Outline of a Theory of Practice. Cambridge: Cambridge University Press. Byczkowska-Owczarek, D. and H. Jakubowska. 2018. 'Sociology of the Body-Teaching Embodied Approach through Autoethnography.' Qualitative Sociology Review 14 (2): 152-164, https://doi.org/10.1017/CBO9780511812507.

Caillois, R. 1958. Les jeux et les hommes: le masque et le virtige. Paris: Gallimard.

Charmaz, K. 2006. Constructing Grounded Theory. A Practical Guide Through Qualitative Analysis. London, Sage, New Delhi: Sage Publications.

Chełmoński, A., K. Kowal and J. Jabłecki. 2015. 'The Physical and Psychosocial Benefits of Upper-Limb Transplantation: A Case Series of 5 Polish Patients.' Annals of Transplantation 20: 639-648, https:// doi.org/10.12659/AOT.893752.

Clarke, A. 1990. 'A Social Worlds Research Adventure. The Case of Reproductive Science.' Pp. 63-93 in Theories of Science in Society, edited by S. E. Cozzens and T. F. Gieryn. Bloomington and Indianapolis, IN: Indiana University Press.

Daly, A. 1997. 'Classical Ballet: A Discourse of Difference.' Pp. 111-121 in Meaning in Motion. New Cultural Studies of Dance. edited by J. C. Desmond. Durham, NC, and London: Duke University Press, https://doi.org/10.1215/9780822397281-006.

Davis, K. 2015. Dancing Tango: Passionate Encounters in a Globalizing World. New York: NYU Press, https://doi.org/10.18574/nyu/9780814760291.001.0001.

Del Vecchio Good, M., P. E. Brodwin, B. Good and A. Kleinman (eds). 1994. Pain as Human Experience. An Anthropological Perspective. Berkeley and Los Angeles, CA: University of Califormia Press.

Desmond, J. C. (ed.) 1997. Meaning in Motion. New Cultural Studies of Dance. Durham, NC, and London: Duke University Press.

Dietz, M. L. 1994. 'On Your Toes: Dancing Your Way into the Ballet World.' Pp. 66-84 in Ethnography as Human Lived Experience, edited by M. Lorenz Dietz, R. Prus and W. Shaffir. Toronto: Copp Clark Longman Ltd.

Ericksen, J. A. 2011. Dance with Me: Ballroom Dancing and the Promise of Instant Intimacy. New York: New York University Press, https://doi.org/10.18574/nyu/9780814722664.001.0001. 
Ericksen, J. A. 2012. 'Dancing the Body Beautiful.' Contexts 1 (2): 48-53, https://doi.org/10.1177/1536504212446460.

Foster, S. L. 1997. 'Dancing Bodies.' Pp. 235-259 Meaning in Motion. New Cultural Studies of Dance. Durham, NC, and London: Duke University Press, https://doi.org/10.1215/9780822397281-013.

Germain-Thomas, P. 2017. 'Development of French Contemporary Dance: An Interaction between Public Intervention and Market Mechanisms.' Dance Research 35 (1): 61-74, https://doi.org/10.3366/drs.2017.0183.

Gobo, G. 2008. Doing Ethnography. Los Angeles, CA, London, New Delhi, Singapore: Sage, https://doi.org/10.4135/9780857028976.

Goffman, E. 2006. Rytuat interakcyjny. (The ritual of interaction) Warsaw: PWN.

Goldberg, M. 1997. 'Homonized Ballerinas.' Pp. 305-320 in Meaning in Motion. New Cultural Studies of Dance, edited by J. C. Desmond. Durham, NC, and London: Duke University Press, https://doi.org/10.1215/9780822397281-017.

Grau, A. 2005. 'When the Landscape Becomes Flesh: An Investigation into Body Boundaries with Special Reference to Tiwi Dance and Western Classical Ballet.' Body and Society 11: 141-163, https://doi.org/10.1177/1357034X05058024.

Hanna, J. L. 1988. Dance, Sex and Society. Signs of Dominance, Defiance, and Desire. Chicago, IL, and London: University of Chicago Press.

Hewitt, A. 2005. Social Choreography: Ideology as Performance in Dance and Everyday Movement. Durham, NC, and London: Duke University Press, https://doi.org/10.1215/9780822386582.

Hindmarsh, J. and A. Pilnick. 2002. 'The Tacit Order of Teamwork: Collaboration and Embodied Conduct in Anesthesia.' The Sociological Quarterly 43 (2): 139-164, https://doi.org/10.1111/j.1533-8525.2002.tb00044.x.

Kacperczyk, A. 2005. 'Zastosowanie koncepcji społecznych światów w badaniach empirycznych.' (The application of social worlds theory in empirical research) Pp. 169-190 in Konstruowanie jaźni i społeczeństwa. Europejskie warianty symbolicznego interakcjonizmu, edited by E. Hałas and K. T. Konecki. Warsaw: Scholar.

Kleinknecht, S. 2007. 'An Interview with Robert Prus: His Career, Contributions, and Legacy as an Interactionist Ethnographer and Social Theorist.' Qualitative Sociology Review 3 (2): 221-288.

Knoblauch, H., A. Baer, E. Laurier, S. Petschke and B. Schnettler. 2008. 'Visual Analysis. New Developments in the Interpretative Analysis of Video and Photography.' Forum Qualitative Sozialforschung / Forum: Qualitative Social Research 9 (3): Art. 14.

Kolb, A. and S. Kalogeropoulou. 2012. 'In Defence of Ballet: Women, Agency and the Philosophy of Pleasure.' Dance Research 30 (2): 107-125, https://doi.org/10.3366/drs.2012.0042.

Konecki, K. T. 2000. Studia z metodologii badań jakościowych. Teoria ugruntowana. (Studies in qualitative methodology: grounded theory) Warsaw: Wydawnictwo Naukowe PWN.

Konecki, K. T. 2005a. ‘Wizualne wyobrażenia. Główne strategie badawcze w socjologii wizualnej a metodologia teoria ugruntowanej.' (Visual imaginations. Main research strategies in visual sociology and methodology of grounded theory) Przeglad Socjologii Jakościowej 1 (1): 42-63.

Konecki, K. T. 2005b. 'The Problem of Symbolic Interaction and of Constructing Self.' Qualitative Sociology Review 1 (1): 68-89.

Konecki, K. T. 2015. Is the Body the Temple of the Soul? Modern Yoga Practice as a Psychological Phenomenon. Lodz: Lodz University Press.

Kraus, L. 2005. 'Dancing the Impossible. Choreography for the Camera.' Dance Magazine (January) 2005: 79-84. 
Kubinowski, D. 1997. Proces wychowania tanecznego w środowisku wiejskim. (The process of dance education in rural community) Lublin: Wydawnictwo Uniwersytetu Marii Curie-Składowskiej.

Lepecki, A. 2006. Exhausting Dance: Performance and the Politics of Movement. New York: Routledge.

Manderson, L. 2011. Surface Tensions. Surgery, Bodily Boundaries and the Social Self. Walnut Creek, CA: Left Coast Press.

Marion, J. S. 2008. Ballroom: Culture and Costume and Competitive Dance. London: Bloomsbury Publishing.

Mauss, M. 1973. Socjologia i antropologia. (Sociology and anthropology) Warsaw: PWN.

McFee, G. 1992. Understanding Dance. London and New York: Routledge.

McMains, J. 2009. 'Dancing Latin/Latin Dancing. Salsa and DanceSport.' Pp. 302-322 in Ballroom, Boogie, Shimmy Sham, Shake: A Social and Popular Dance Reader, edited by J. Malnig. Urbana and Chicago, IL: University of Illinois Press.

McMains, J. 2019. 'Reclaiming Competitive Tango. The rise of Argentina's Campeonato Mundial.' Pp. 305-306 in The Oxford Handbook of Dance and Competition, edited by S. Dodds. New York: Oxford University Press, https://doi.org/10.1093/oxfordhb/9780190639082.013.12.

Merleau-Ponty, M. 2001. Fenomenologia percepcji. (Phenomenology of perception) Warsaw: Fundacja Aletheia, https:/ / doi.org/10.4324/9780203994610.

Nelson, E. D. 2001. 'The Things That Dreams Are Made On: Dreamwork and the Socialization of "Stage Mothers".' Qualitative Sociology 24 (4): 439-458, https://doi.org/10.1023/A:1012227513036.

Olszewski, B. 2008. 'El cuerpo del Baile: The Kinetic and Social Fundaments of Tango.' Body and Society 14 (2): 63-81, https://doi.org/10.1177/1357034X08090698.

Picard, C. J. 2002. "Dancing through Different Worlds: An Autoethnography of the Interactive Body and Virtual Emotions in Ballroom Dance.' Qualitative Inquiry 8 (3): 348-361, https://doi.org/10.1177/10778004008003009.

Picard, C. J. 2006. From Ballroom to Dance Sport: Aesthetics, Athletics and Body Culture. Albany, NY: State University of New York Press.

Prus, R. 1994. 'Approaching the Study of Human Group Life: Symbolic Interaction and Ethnographic Inquiry.' Pp 10-29 in Ethnography as Human Lived Experience, edited by M. L. Dietz, R. Prus and W. Shaffir. Toronto: Copp Clark Longman Ltd.

Rambo Ronai, C. 1992. 'Managing Aging in Young Adulthood. The Aging Table Dancer.' Journal of Aging Studies 6 (4): 307-317, https://doi.org/10.1016/0890-4065(92)90014-W.

Rambo Ronai, C. and C. Ellis. 1989. 'Turn-Ons for Money.' Journal of Contemporary Ethnography 18 (3): 271-298, https://doi.org/10.1177/089124189018003002.

Rambo Ronai, C. and R. Cross. 1998. 'Dancing with Identity: Narrative Resistance Strategies of Male and Female Stripteasers.' Deviant Behavior 19 (2): 99-119, https://doi.org/10.1080/01639625.1998.9968078.

Rambo, C., S. R. Presley and D. Mynatt. 2006. 'Claiming the Bodies of Exotic Dancers: The Problematic Discourse of Commodification.' Pp 213-228 in Body/Embodiment: Symbolic Interaction and the Sociology of the Body, edited by D. Waskul and P. Vannini. Aldershot, Burlington: Ashgate.

Schlesinger, L. 1996. 'Chronic Pain, Intimacy, and Sexuality: A Qualitative Study of Women Who Live with Pain.' The Journal of Sex Research 33 (3): 249-256, https://doi.org/10.1080/00224499609551841.

Strauss, A. and J. Corbin. 1990. Basics of Qualitative Research. Grounded Theory Procedures and Techniques. Newbury Park, London, New Delhi: Sage Publications.

Taylor, J. 1998. Paper Tangos. Durham, NC: Duke University Press, https://doi.org/10.1215/9780822378983. 
Thiel, D. 2007. 'Class in Construction: London Building Workers, Dirty Work and Physical Cultures.' The British Journal of Sociology 58 (2): 227-251, https://doi.org/10.1111/j.1468-4446.2007.00149.x.

Thomas, H. 1995. Dance, Modernity, and Culture: Explorations in the Sociology of Dance. London: Routledge.

Thomas, H. 2003. The Body, Dance, and Cultural Theory. New York: Palgrave Macmillan, https://doi.org/10.1007/978-1-137-48777-3.

Turner, B. S. 1984. The Body and Society. Oxford: Basil Blackwell.

Wacquant, L. 2004. Body and Soul. Notebooks of an Apprentice Boxer. New York: Oxford University Press.

Wainwright, S. P. and B. S. Turner. 2004. 'Epiphanies of Embodiment: Injury, Identity and the Balletic Body.' Qualitative Research 4 (3): 311-337, https://doi.org/10.1177/1468794104047232.

Wainwright, S. P., C. Williams and B. S. Turner. 2006. 'Varieties of Habitus and Embodiment of Ballet.' Qualitative Research 6 (4): 535-558, https://doi.org/10.1177/1468794106068023.

Wall, S. 2008. 'Easier Said, Than Done: Writing an Autoethnography.' International Journal of Qualitative Methods 7 (1): 38-53, https://doi.org/10.1177/160940690800700103. 